Research Article

\title{
Preparation of Fe(II)/MOF-5 Catalyst for Highly Selective Catalytic Hydroxylation of Phenol by Equivalent Loading at Room Temperature
}

\author{
Bai-Lin Xiang $\mathbb{D}^{1,2,3}$ Lin Fu, $^{1}$ Yongfei Li $\mathbb{D}^{1},{ }^{1}$ and Yuejin Liu $\mathbb{D}^{1}$ \\ ${ }^{1}$ College of Chemistry Engineering, Xiangtan University, Xiangtan 411000, China \\ ${ }^{2}$ College of Chemistry and Materials Engineering, Huaihua University, Huaihua 418000, China \\ ${ }^{3}$ Hunan Engineering Laboratory for Preparation Technology of Polyvinyl Alcohol (PVA) Fiber Material, \\ College of Chemistry and Materials Engineering, Huaihua University, Huaihua 418000, China \\ Correspondence should be addressed to Yongfei Li; liyongfei98@163.com and Yuejin Liu; xdlyj@163.com
}

Received 27 June 2019; Revised 28 August 2019; Accepted 30 September 2019; Published 7 November 2019

Academic Editor: Cláudia G. Silva

Copyright (c) 2019 Bai-Lin Xiang et al. This is an open access article distributed under the Creative Commons Attribution License, which permits unrestricted use, distribution, and reproduction in any medium, provided the original work is properly cited.

\begin{abstract}
The metal-organic framework MOF- 5 was synthesized by self-assembling of $\mathrm{Zn}\left(\mathrm{NO}_{3}\right)_{2} \cdot 7 \mathrm{H}_{2} \mathrm{O}$ and $\mathrm{H}_{2} \mathrm{BDC}$ using DMF as solvent by the direct precipitation method and loaded with $\mathrm{Fe}^{2+}$ by the equivalent loading method at room temperature to prepare $\mathrm{Fe}(\mathrm{II}) /$ MOF- 5 catalyst and the microstructure, phases, and pore size of which was characterized by IR, XRD, SEM, TEM, and BET. It was found that Fe(II)/MOF-5 had high specific surface and porosity like MOF-5 and uniform pore distribution, and the pore size is $1.2 \mathrm{~nm}$. In order to study the catalytic activity and reaction conditions of Fe(II)/MOF-5, it was used to catalyze the hydroxylation reaction of phenol with hydrogen peroxide. The results showed that the dihydroxybenzene yield of $53.2 \%$ and the catechol selectivity of $98.6 \%$ were obtained at the $\mathrm{Fe}^{2+}$ content of 3 wt.\%, the mass ratio of $\mathrm{Fe}(\mathrm{II}) / \mathrm{MOF}-5$ to phenol of 0.053 , the reaction temperature of $80^{\circ} \mathrm{C}$, and the reaction time of $2 \mathrm{~h}$.
\end{abstract}

\section{Introduction}

Dihydroxybenzenes mainly include catechol and hydroquinone and are important organic intermediates for synthesis of carbofuran, propoxur, berberine and epinephrine, vanillin, piperonal, etc. In addition, dihydroxybenzenes are used for dyes, photosensitive materials, electroplating materials, special inks, auxiliaries, etc [1]. As an important fine chemical intermediate product, catechol (CAT) is widely used in the fields of pesticides (about half of the global catechol consumption), spices, and medicine [2].

The process of dihydroxybenzene preparation from direct oxidization of phenol by hydrogen peroxide was a green production process because of simple process, mild reaction conditions, water as by-product, and no environmental pollution [3-6]. However, a catalyst is must required for direct oxidization of phenol by hydrogen peroxide, i.e., hydroxylation of phenol. Thus, it is very important to select a suitable catalyst for phenol hydroxylation. The catalysts for phenol hydroxylation include modified molecular sieves, composite metal oxides, organic metal complexes, etc [7-9]. It has been reported that the phenol conversion of these catalysts for phenol hydroxylation was usually between $40 \%$ and $60 \%$, and the catechol selectivity was seldom more than 75\% [10-12]. According to Adam et al. [13], the molecular sieve catalyst $(\mathrm{Fe} / \mathrm{KL})$ catalyzed phenol hydroxylation with the conversion of $93.4 \%$, but the catechol selectivity was only $77.47 \%$. Zheng et al. [14] prepared the $\mathrm{CD} /$-MOF-cat catalyst which catalyzed phenol hydroxylation with the conversion of $86 \%$ and catechol selectivity of $73.7 \%$. Hu [15] synthesized the hexadecyl pyridinium salt of As-Mo-V heteropolyacid, which catalyzed phenol hydroxylation in acetonitrile as 
solvent with the catechol selectivity of $87.3 \%$, but the phenol conversion was only $17.1 \%$. Therefore, it is very important to develop a catalyst with high phenol conversion and catechol selectivity.

Metal-organic frameworks (MOFs) are new nanoporous frameworks with periodic network structure formed by self-assembling of nitrogen or oxygen-containing organic ligands and transition metal ions through complexation [16]. MOFs have well-ordered tunable porous structures with a wide range of pore sizes and exceptional textural properties of high surface areas and high pore volumes, which can afford a variety of applications in gas adsorption/separation and heterogeneous catalysis [17]. When MOFs is used as a homogeneous catalyst, it has been used for the following reactions: (a) aerobic oxidation of tetralin [18, 19], (b) phenol hydroxylation [20], (c) oxidative desulfurization of dibenzothiophene [21], (d) Knoevenagel condensation reaction $[22,23]$, (e) one pot deacetalization-nitroaldol reaction [24], (f) Friedel-Craft acylation [25], (g) $\mathrm{CO}_{2}$ cycloaddition of epoxides [26], (h) heck reaction [27], and (i) epoxidation of alkenes [28]. As a typical representative of the metal-organic framework complex family, MOF-5 was a framework with a threedimensional structure, high specific surface, and well-defined pore structure formed by connecting an inorganic group, $\left[\mathrm{Zn}_{4} \mathrm{O}\right]$, consisting of four zinc and one $\mathrm{O}$ to P-phenylene dimethyl [29]. It has much higher specific surface and pore volume than activated carbon, zeolite molecular sieves, and silica. Kaye et al. in Yaghi team [30] reported a MOF-5 with the specific surface area of $2900 \mathrm{~m}^{2} /$ g. Perez et al. [31] reported a MOF-5 with the specific surface area of $3362 \mathrm{~m}^{2} / \mathrm{g}$. MOF-5 has a shape-selective effect in specific catalytic reactions because of its controllable pore size and orderly pore size [32-35], which is helpful to improve the selectivity of the reactions. MOF-5 was also often used as a carrier to support different catalytic active sites, such as $\mathrm{Pt}, \mathrm{Au}$, and $\mathrm{Pd}$, to prepare MOF-based catalysts [36-39] for different heterogeneous catalytic reactions, with good catalytic effect. For example, Liu et al. [40] have reported the catalyst $\mathrm{Au} / \mathrm{MOF}-5$ which supported $\mathrm{Au}$ on a functionalized MOF-5 by the impregnation method. The results showed that the Au/MOF-5 catalyst displayed high activity and $100 \%$ selectivity for propargylamines.

In addition, many transition metals, such as $\mathrm{Cu}, \mathrm{Mn}$, Mo, and Fe, have the activity to catalyze phenol hydroxylation, but Fe-supported catalysts are used more frequently. For example, the Fe-supported bentonite catalyst prepared by RESTU [41] and Fe/Al-MCM-41 prepared by Preethi et al. [42] show better catalytic activity than other transition metals. Also, some Fe-supported catalysts showed good selectivity in some oxidation reactions $[43,44]$.

In this paper, $\mathrm{Fe}^{2+}$-supported MOF- 5 was synthesized by the direct precipitation method and used for phenol hydroxylation. MOF-5 cannot withstand high temperature above $400^{\circ} \mathrm{C}$ [45], so $\mathrm{Fe}(\mathrm{II}) / \mathrm{MOF}-5$ was prepared by equivalent loading of $\mathrm{Fe}^{2+}$ at low temperature [46] and used to catalyze hydroxylation of phenol by hydrogen peroxide in order to study the performance of the Fe(II)/MOF- 5 catalyst and technological conditions of hydroxylation of phenol by hydrogen peroxide.

\section{Experimental}

2.1. Reagents and Apparatuses. All chemicals in this study were directly used without any purification. $\mathrm{Zn}\left(\mathrm{NO}_{3}\right)_{2}$. $6 \mathrm{H}_{2} \mathrm{O}$, terephthalicacid, $\mathrm{DMF}(\mathrm{N}, \mathrm{N}$-dimethylformamide), triethylamine, $\mathrm{FeSO}_{4} \cdot 7 \mathrm{H}_{2} \mathrm{O}$, phenol, hydrogen peroxide $(30 \%)$, deionized water, and ethyl acetate are all chemically pure.

A 3-mouth flask, EL204 analytical balance, round-bottom flask, beaker, funnel, DF-101S constant temperature magnetic stirrer, liquid separating funnel, gas chromatography-mass spectrometry were used (Shimadzu GCMS 2010-plus).

2.2. Direct Precipitation Synthesis of MOF-5. $3 \mathrm{~g}$ of $\mathrm{Zn}\left(\mathrm{NO}_{3}\right)_{2} \cdot 6 \mathrm{H}_{2} \mathrm{O}$ and $1.275 \mathrm{~g}$ of di-2-hydroxyethyl terephthalate were weighed to three flasks. $100 \mathrm{~mL}$ of DMF was added. The mixture was well mixed at room temperature until a clear solution was obtained. Triethylamine $(4 \mathrm{~g}, 5.5 \mathrm{~mL})$ was dropwise added under violent agitation. The solution gradually became turbid. After that, the solution was stirred for $3 \mathrm{~h}$ and filtered at vacuum. The cake was washed with DMF $(3 \times 20 \mathrm{~mL})$ and dried at $120^{\circ} \mathrm{C}$ to form MOF-5 [46].

2.3. Preparation of $\mathrm{Fe}(\mathrm{II}) / \mathrm{MOF}-5$ by the Equivalent Loading Method. Based on $5 \mathrm{~g}$ of MOF-5, the mass of $\mathrm{FeSO}_{4} \cdot 7 \mathrm{H}_{2} \mathrm{O}$ was calculated according to the $\mathrm{Fe}^{2+}$ loading of $1 \%, 2 \%, 3 \%$, $4 \%, 5 \%, 6 \%$, and $7 \%$ (wt. $\%$ ), respectively. $\mathrm{FeSO}_{4} \cdot 7 \mathrm{H}_{2} \mathrm{O}$ was weighed to a conical bottle containing DMF (the volume of DMF was equal to that of $5 \mathrm{~g}$ of MOF-5) and dissolved under agitation at room temperature. $5 \mathrm{~g}$ of MOF- 5 was added to the solution. Meanwhile, MOF-5 was just immersed in DMF solution. The solution was well mixed and dried at vacuum at $90^{\circ} \mathrm{C}$ for $2 \mathrm{~h}$ to obtain $\mathrm{Fe}(\mathrm{II}) / \mathrm{MOF}-5$ with the $\mathrm{Fe}^{2+}$ loading of $1 \%, 2 \%, 3 \%, 4 \%, 5 \%, 6 \%$, and $7 \%$.

2.4. Hydroxylation of Phenol. $0.5 \mathrm{~g}$ of Fe(II)/MOF-5, $9.0 \mathrm{~mL}$ of phenol, $160 \mathrm{~mL}$ of hydrogen peroxide $(30 \%)$, and $300 \mathrm{~mL}$ of deionized water were taken to a round-bottom flask, where the reaction lasted for $1 \sim 3 \mathrm{~h}$ under magnetic agitation at $80^{\circ} \mathrm{C}$. At the end of the reaction, the solution was filtrated. The filtrate was extracted by ethyl acetate three times. The extract was tested on phenol and dihydroxybenzene contents by gas chromatography-mass spectrometry (GCMS 2010plus). The filtrate was distilled to remove all liquids and obtain a small amount of solid (tar) on the flask wall. The tar was weighed. The yield of catechol, hydroquinone, benzodiazepine, and the selectivity of catechol were calculated by the following formula: 


$$
\begin{aligned}
X_{\text {phenol }} & =\frac{m_{\text {phenol }}-m_{\text {phenol }(\mathrm{R})}}{m_{\text {phenol }}}, \\
S_{\mathrm{CAT}} & =\frac{94 m_{\mathrm{CAT}}}{110\left(m_{\text {phenol }}-m_{\text {phenol }(\mathrm{R})}\right)}, \\
Y_{\mathrm{CAT}} & =X_{\text {phenol }} \cdot S_{\mathrm{CAT}}, \\
S_{\mathrm{HQ}} & =\frac{94 m_{\mathrm{HQ}}}{110\left(m_{\text {phenol }}-m_{\text {phenol }(\mathrm{R})}\right)}, \\
Y_{\mathrm{DHB}} & =Y_{\mathrm{CAT}}+Y_{\mathrm{HQ}}, \\
Y_{\mathrm{HQ}} & =X_{\text {phenol }} \cdot S_{\mathrm{HQ}},
\end{aligned}
$$

where $m_{\text {phenol }}$ is the mass of phenol before reaction, $m_{\text {phenol(R) }}$ is the mass of phenol after reaction, $X_{\text {phenol }}$ is the conversion of phenol, $S_{\mathrm{CAT}}$ is the selectivity of catechol, $S_{\mathrm{HQ}}$ is the selectivity of hydroquinone, $Y_{\mathrm{CAT}}$ is the yield of catechol, $Y_{\mathrm{HQ}}$ is the yield of hydroquinone, and $Y_{\mathrm{DHB}}$ is the yield of benzodiazepine.

2.5. Characterization of Catalyst. The catalyst samples were measured using a Rigaku UltimaIV XRD system with $\mathrm{Cu}-\mathrm{K} \alpha$ radiation $(\lambda=0.1542 \mathrm{~nm})$. The target voltage and current were $40 \mathrm{kV}$ and $30 \mathrm{~mA}$, respectively. The $2 \theta$ scan range and rate were $3 \sim 50^{\circ}$ and $8^{\circ} \mathrm{min}^{-1}$, respectively. A FTS 165 Fourier transform infrared spectrometer was used to measure the catalyst samples with $\mathrm{KBr}$ pellets. Transmission light was used to scan within a range of $4000 \sim 400 \mathrm{~cm}^{-1}$. The catalyst samples were observed under a ZEISS Sigma HD field emission scanning electron microscopy (FESEM). The accelerating voltage was $8 \mathrm{kV}$. The morphology was observed using the secondary electron detectors in lens. Meanwhile, the element contents in the samples were analyzed using an Oxford X-Max electric energy spectrum meter (X-MaxN). TEM of the samples was obtained using a JEOL JEM-2010 UHR transmission electron microscope with an accelerating voltage of $200 \mathrm{kV}$. The Brunauer-Emmett-Teller (BET) specific surface areas were measured on Belsorp-Mini II analyzer (Japan).

\section{Results and Discussion}

\subsection{Catalyst Structure Characterization}

3.1.1. XRD Analysis. Figure 1 shows the Fe(II)/MOF-5 samples with different $\mathrm{Fe}^{2+}$ loadings $(0 \%, 1 \%, 2 \%, 3 \%, 4 \%$, $5 \%, 6 \%$, and $7 \%$, respectively). The main four characteristic peaks of MOF-5 were at $2 \theta=6.8^{\circ}, 9.7^{\circ}, 13.7^{\circ}$, and $15.4^{\circ}$ [46]. $2 \theta=6.8^{\circ}$ in the small corner area represented $<200>$ crystal plane, and $2 \theta=9.7^{\circ}$ represented $<220>$ crystal plane [47]. It could be seen from Figure 1 that the characteristic peaks of the prepared MOF-5 were consistent with those reported in the literature. We also found that the characteristic peak intensity of the catalyst decreased with the increase in $\mathrm{Fe}^{2+}$ loading from Figure 1. This was because the widened diffraction peaks resulting from fineness and small grain size of

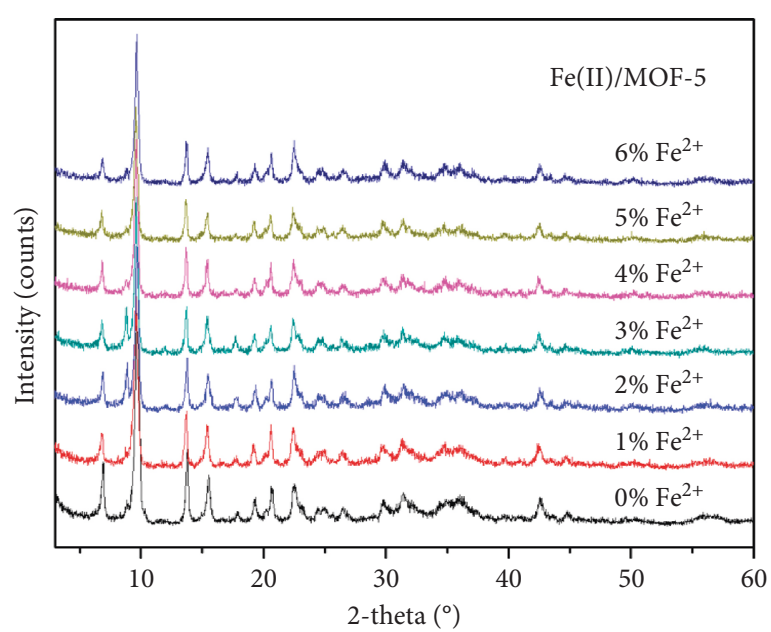

FIGURE 1: XRD patterns of Fe(II)/MOF-5.

$\mathrm{Fe}^{2+}$-supported catalyst crystal. But $\mathrm{Fe}^{2+}$ had little influence on the crystal structure of MOF- 5 because the characteristic peaks of the sample still existed. However, no obvious characteristic peak of $\mathrm{Fe}^{2+}$ was found in XRD spectra maybe due to the low loading of $\mathrm{Fe}^{2+}$ or the small size and high dispersion of $\mathrm{Fe}^{2+}$ particles. In addition, MOF-5 and $\mathrm{Fe}(\mathrm{II}) /$ MOF-5 were very different in color. MOF- 5 was white, while $\mathrm{Fe}(\mathrm{II}) / \mathrm{MOF}-5$ was brown. $\mathrm{Fe}(\mathrm{II}) / \mathrm{MOF}-5$ became darker with the increase in $\mathrm{Fe}^{2+}$ loading.

3.1.2. Infrared Spectrometry Analysis. Figure 2 shows the infrared spectra of $\mathrm{Fe}(\mathrm{II}) / \mathrm{MOF}-5$ with different $\mathrm{Fe}(\mathrm{II}) /$ MOF-5 loadings. It could be seen from Figure 2 that MOF-5 and Fe(II)/MOF-5 samples basically had the characteristic peaks. The peak at $750 \mathrm{~cm}^{-1}$ was the stretching vibration of $\mathrm{Zn}-\mathrm{O}$ in tetrahedral $\mathrm{Zn}_{4} \mathrm{O}$ crystal clusters. The peaks at $1388 \mathrm{~cm}^{-1}$ and $1580 \mathrm{~cm}^{-1}$ were two strong absorption peaks, i.e., stretching vibration peaks of $-\mathrm{C}=\mathrm{O}$ in -COO- $\mathrm{Zn}^{2+}$, including asymmetric and symmetric stretching vibration peaks of- $\mathrm{C}=\mathrm{O}$, respectively, and the peak at $1652 \mathrm{~cm}^{-1}$ was the asymmetrical stretching vibration of the $\mathrm{C}-\mathrm{O}-\mathrm{O}$ bond. It could be seen from comparison of the infrared spectra that the loading of $\mathrm{Fe}^{2+}$ did not influence the chemical structure of MOF-5.

3.1.3. SEM and Energy Dispersive Spectrometry Analysis. Figure 3(a) shows the SEM images of MOF-5, and Figure 3(b) shows the SEM photograph of Fe(II)/MOF-5 with $\mathrm{Fe}^{2+}$ loading of $3 \%$.

Figure 3(a) shows that MOF-5 had a lot of wafer with the size of $50-300 \mathrm{~nm}$ and had relatively smooth surface and some voids and channels between particles. Figure 3(b) shows that $\mathrm{Fe}(\mathrm{II}) / \mathrm{MOF}-5$ with $\mathrm{Fe}^{2+}$ loading of $3 \%$ had similar morphology compared with MOF-5; i.e., some of the crystalline blocks are stuck together, but there were had more voids between the crystalline blocks than MOF-5.

Figure 4 is the energy dispersive spectrum of $\mathrm{Fe}(\mathrm{II}) /$ MOF-5 with $3 \% \mathrm{Fe}^{2+}$ loading. It could be seen that Fe atoms present in $\mathrm{Fe}(\mathrm{II}) / \mathrm{MOF}-5$, showing successful loading of $\mathrm{Fe}^{2+}$ 


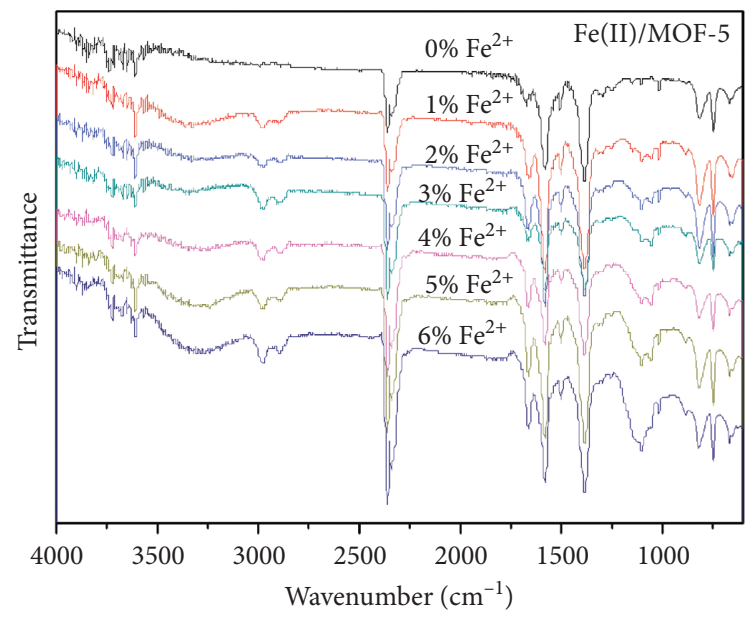

Figure 2: IR spectra of Fe (II)/MOF-5.
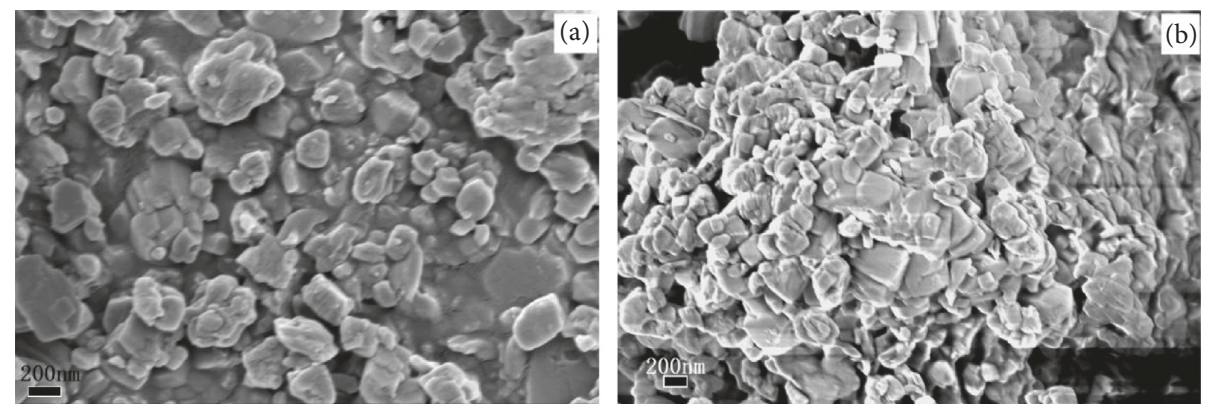

Figure 3: SEM images of MOF-5 and Fe(II)/MOF-5 $\left(3 \% \mathrm{Fe}^{2+}\right)$.

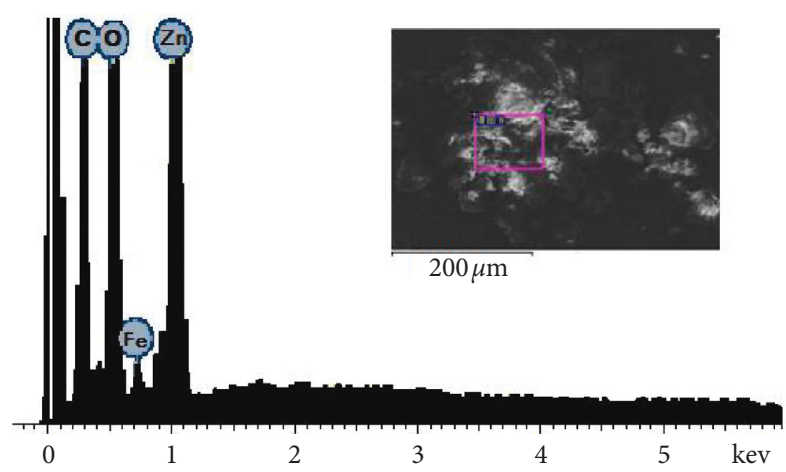

Figure 4: X-MaxN energy spectrum of Fe(II)/MOF-5 $\left(3 \% \mathrm{Fe}^{2+}\right)$.

onto MOF-5. The loading (about $3.4 \mathrm{wt} . \%$ ) of $\mathrm{Fe}^{2+}$ calculated from the EDS (Table 1) is near to the initial adding amount (3 wt.\%). The catalyst of Fe(II)/MOF-5 (containing 3\% $\mathrm{Fe}^{2+}$ ) was further characterized by element mapping. The results are shown in Figure 5. We found that the catalyst contains C, $\mathrm{O}, \mathrm{Zn}$, and Fe elements. And we can clearly see that the catalyst has relatively uniform Fe distribution, indicating uniform loading of Fe ions on the catalysts.

3.1.4. TEM and Pore Size Distribution. Figures 6(a) and 6(b) are TEM images of MOF-5 and $\mathrm{Fe}(\mathrm{II}) / \mathrm{MOF}-5$ catalyst, respectively. It is clear that MOF- 5 and $\mathrm{Fe}(\mathrm{II}) / \mathrm{MOF}-5$ both
TABle 1: Element content of Fe(II)/MOF-5 $\left(3 \% \mathrm{Fe}^{2+}\right)$.

\begin{tabular}{lcccc}
\hline Element & $\mathrm{C}$ & $\mathrm{O}$ & $\mathrm{Fe}$ & $\mathrm{Zn}$ \\
\hline Mass (\%) & 36.81 & 38.55 & 3.40 & 21.24 \\
Mol (\%) & 52.47 & 40.93 & 1.04 & 5.56 \\
\hline
\end{tabular}

had regular channel structures, and the channel width was about 1-2 nm. Also, it could be seen that $\mathrm{Fe}^{2+}$ loading did not greatly influence the channel structure of MOF-5. Figure 7 shows the pore size distribution of MOF- 5 and $\mathrm{Fe}$ (II)/MOF5 with $\mathrm{Fe}^{2+}$ loading of $1 \%, 3 \%$, and 5\%, respectively. Their pore sizes were mainly at $1.2 \mathrm{~nm}$, corresponding to those size observed by TEM.

\subsection{Phenol Hydroxylation}

3.2.1. Comparison of Catalytic Activity. The results of phenol hydroxylation by hydrogen peroxide which was catalyzed by $\mathrm{Fe}(\mathrm{II}) / \mathrm{MOF}-5$ catalysts with different $\mathrm{Fe}^{2+}$ loadings (1\%, 2\%, $3 \%, 4 \%, 5 \%, 6 \%$, and $7 \%$, respectively) are shown in Table 2 .

It could be concluded from Table 1 that (1) no product was generated when MOF-5 was used as catalyst in a blank experiment, (2) MOF-5 with $\mathrm{Fe}^{2+}$ loading of $3 \%$ had the best catalytic effect and provided the dihydroxybenzene yield of $53.2 \%$ (Figure 8), (3) no hydroquinone was detected, and the selectivity of catechol was $98.6 \%$ when the weight of tar was taken into account. With increasing $\mathrm{Fe}^{2+}$ loading below $3 \%$, 

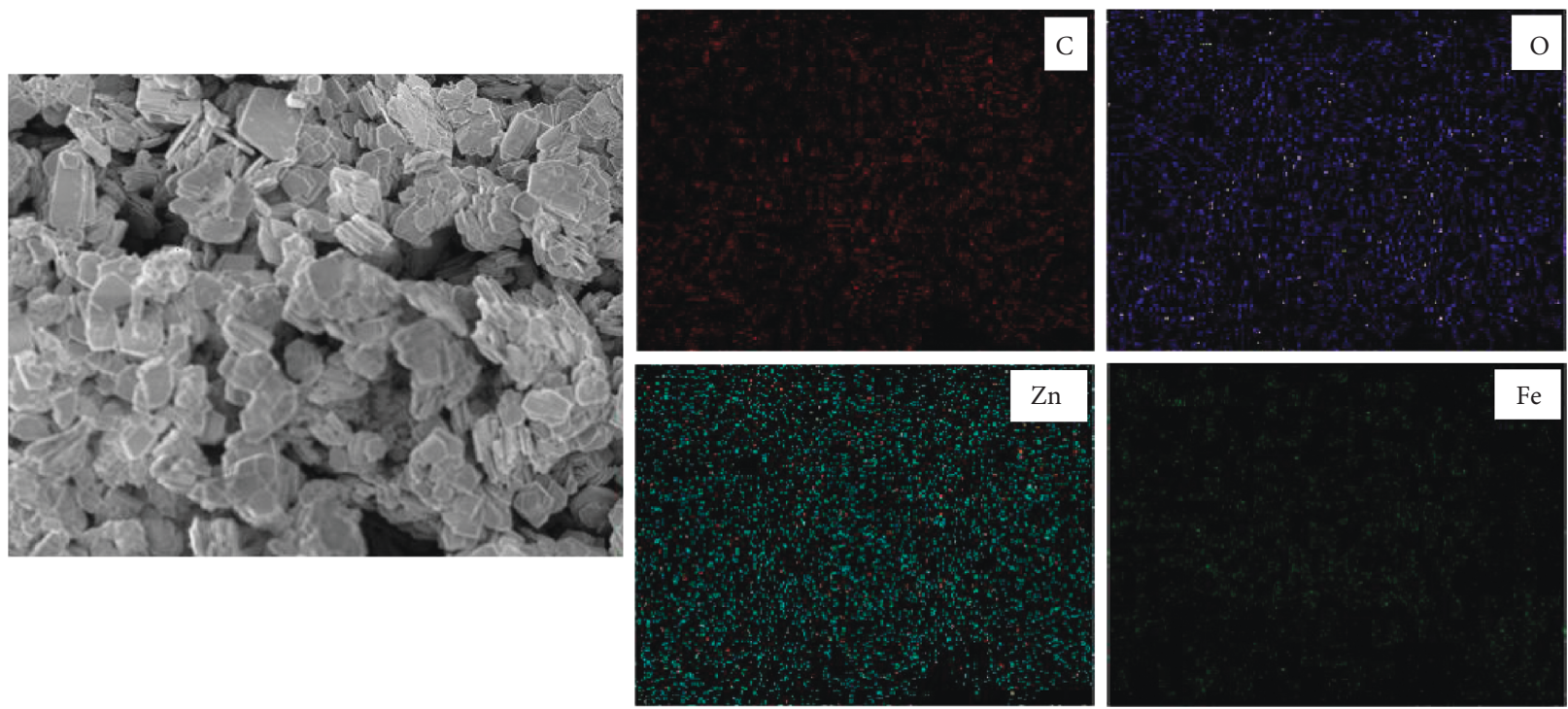

Figure 5: Element mapping of $\mathrm{Fe}(\mathrm{II}) / \mathrm{MOF}-5\left(3 \% \mathrm{Fe}^{2+}\right)$.
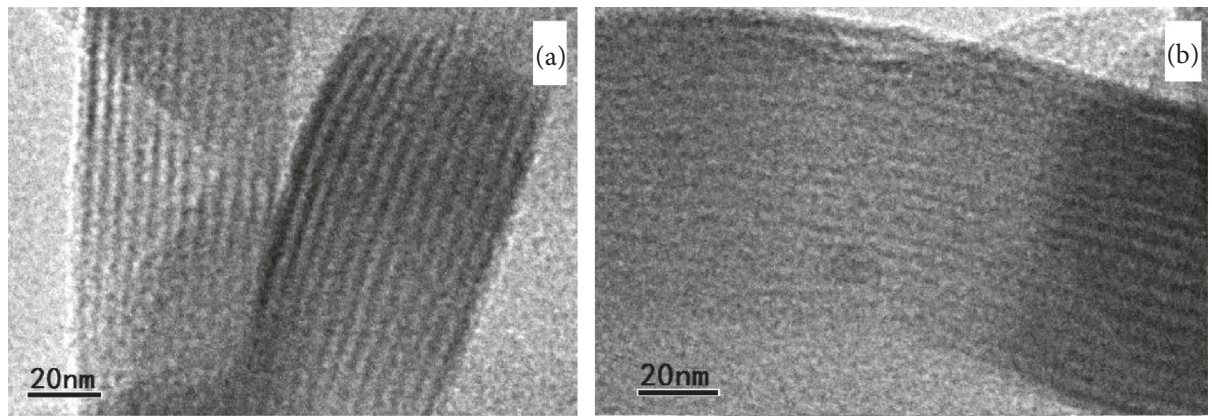

Figure 6: TEM images of the samples (a) MOF-5 and (b) Fe(II)/MOF-5.

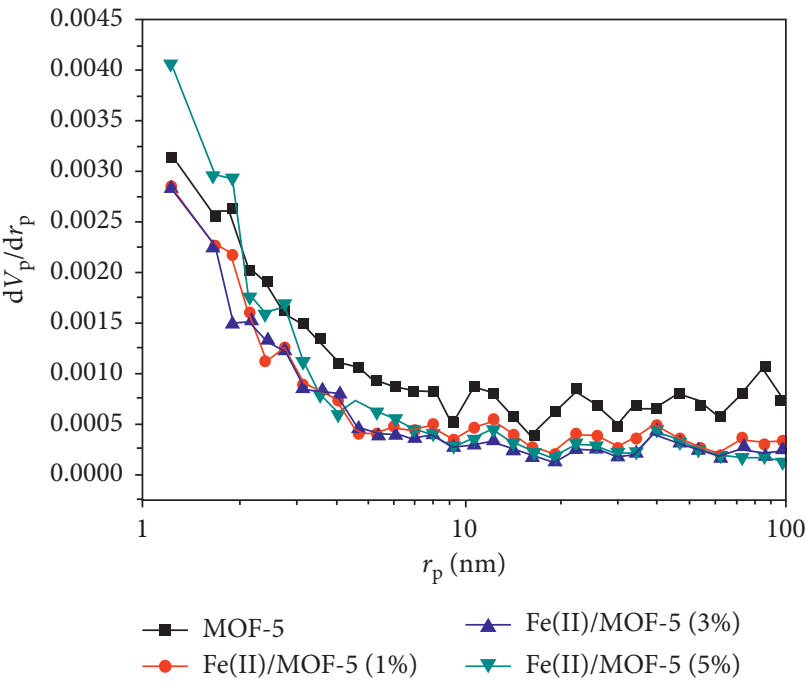

Figure 7: Pore size distribution of the samples.

the yield of dihydroxybenzene increased. However, with increasing $\mathrm{Fe}^{2+}$ loading above 3\%, the yield of dihydroxybenzene decreased gradually. This might be because the increase in $\mathrm{Fe}^{2+}$ loading easily led to the rapid decomposition of $\mathrm{H}_{2} \mathrm{O}_{2}$ into oxygen and water, resulting in the lower utilization rate of $\mathrm{H}_{2} \mathrm{O}_{2}$ and lower catalytic efficiency $[10,48]$. In addition, it has been found that the amount of bubbles increased with the increasing content of $\mathrm{Fe}$, which indirectly proves that the increase in $\mathrm{Fe}$ will accelerate the decomposition of $\mathrm{H}_{2} \mathrm{O}_{2}$ into $\mathrm{H}_{2} \mathrm{O}$ and $\mathrm{O}_{2}$.

No matter what the loading of $\mathrm{Fe}^{2+}$ was, the selectivity of catechol was relatively high (up to 98.6\%) in the reaction. This might be due to the small and uniform pore size $(1.2 \mathrm{~nm})$ of $\mathrm{Fe}(\mathrm{II}) / \mathrm{MOF}-5$ (Figures 6 and 7). TEM image showed that the pore size distribution of MOF-5 was uniform, which made small size single molecule phenol or catechol easy to diffuse in the pore. However, hydroxyl groups of hydroquinone could easily interact with each other to form a multimolecular hydrogen bond association product [49] (Figure 9), and this makes it difficult to diffuse in the channels of catalyst. Therefore, those lead to a shapeselection effect [32], and the selectivity of catechol was very high. However, dihydroxybenzene was easily oxidized severely to macromolecular substances, such as tar [50], which causes catechol selectivity below $100 \%$.

Compared with our previous work [51], the catalytic activity of $\mathrm{Fe}^{2+} / \mathrm{MOF}-5$ showed a higher yield of dihydroxybenzene (53.2\%) than that of pure $\mathrm{Fe}^{3+} / \mathrm{MOF}-5$ (37\%), 
TABLE 2: Catalytic experimental results of phenol hydroxylation.

\begin{tabular}{lccccc}
\hline Catalyst & $\begin{array}{c}\text { Content of } \mathrm{Fe}^{2+} \\
\text { (mass \%) }\end{array}$ & $\begin{array}{c}\text { Catechol yield } \\
\text { (mass \%) }\end{array}$ & $\begin{array}{c}\text { Hydroquinone yield } \\
\text { (mass \%) }\end{array}$ & $\begin{array}{c}\text { Dihydroxy benzene } \\
\text { yield (mass \%) }\end{array}$ & $\begin{array}{c}\text { Catechol selectivity } \\
\text { (mass \%) }\end{array}$ \\
\hline & 0 & - & - & - & - \\
& 1 & 24.2 & 2.6 & 27.8 & 86 \\
Fe(II)/MOF-5 & 2 & 42.3 & 1.2 & 43.5 & 95.9 \\
& 3 & 53.2 & - & 53.2 & 90 \\
& 4 & 40 & - & 23.3 & 97.4 \\
& 5 & 23.3 & - & 15.1 & 95.6 \\
\hline
\end{tabular}

Reaction conditions: reaction temperature, $80^{\circ} \mathrm{C}$; reaction time, $2 \mathrm{~h}$; catalyst-to-phenol mass ratio, 0.053 .

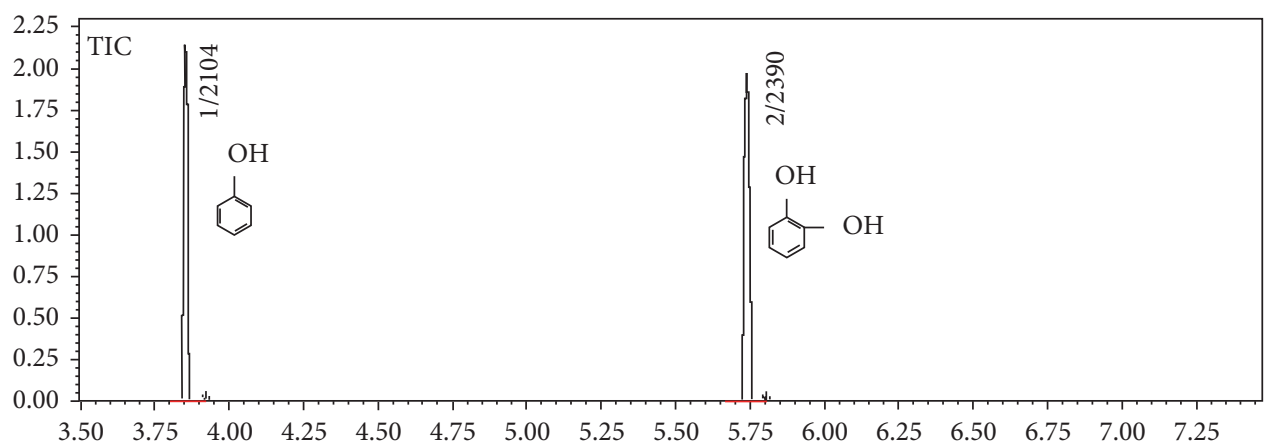

FIgURE 8: GC-MS test of phenol hydroxylation over Fe(II)/MOF-5 (3\%).<smiles>O=Cc1ccc(O)cc1Oc1ccc(O)cc1Oc1ccc(O)c(C=Cc2cc(O)ccc2O)c1</smiles>

FIGURE 9: Multimolecule association of hydrogen bonds among hydroxyls of hydroquinone to form hydroquinone.

due the oxidation of $\mathrm{Fe}^{2+}$ to $\mathrm{Fe}^{3+}$ by $\mathrm{H}_{2} \mathrm{O}_{2}$ in the liquid phase, which resulted in the coexistence of $\mathrm{Fe}^{2+}$ and $\mathrm{Fe}^{3+}$, and thus in an increase in dihydroxybenzene yield [52].

3.2.2. Influence of Reaction Temperature. The hydroxylation of phenol by hydrogen peroxide was catalyzed by $\mathrm{Fe}(\mathrm{II}) /$ MOF-5 with $\mathrm{Fe}^{2+}$ loading of $3 \%$ at different reaction temperatures. The results are listed in Table 3 .

It could be seen from Table 3 that almost no dihydroxybenzene was formed at $50 \sim 60^{\circ} \mathrm{C}$. The yield of dihydroxybenzene was $48.4 \%$, and the selectivity of catechol was $85.4 \%$ at $70^{\circ} \mathrm{C}$; the yield of catechol was $53.2 \%$, and the selectivity of catechol was $98.6 \%$ at $80^{\circ} \mathrm{C}$. The optimal reaction temperature was $80^{\circ} \mathrm{C}$ due to too fast decomposition of $\mathrm{H}_{2} \mathrm{O}_{2}$ above $80^{\circ} \mathrm{C}$.

3.2.3. Influence of Reaction Time. Table 4 shows the effect of reaction time on the hydroxylation of phenol catalyzed by $\mathrm{Fe}(\mathrm{II}) / \mathrm{MOF}-5$ with $\mathrm{Fe}^{2+}$ loading of $3 \%$. It could be seen that almost no product was formed at $0.5 \mathrm{~h}$; with the increase in reaction time, the yield of catechol first increased and then decreased, and the selectivity of catechol was above than 95\%; the produced catechol was easily oxidized to macromolecular substances, such as tar [50], resulting in a decrease in the dihydroxybenzene yield. The solutions had significantly darker color at $3 \mathrm{~h}$ than at $2 \mathrm{~h}$ (Figure 10); after complete evaporation of each solution, it was found that the tar content was higher at $3 \mathrm{~h}$ than that at $2 \mathrm{~h}$, indicating that with the increase in reaction time, more tar would be produced. Thus, the optimum reaction time was $2 \mathrm{~h}$.

3.2.4. Influence of Catalyst Dosage. Table 5 shows the effect of $\mathrm{Fe}(\mathrm{II}) / \mathrm{MOF}-5$ catalyst consumption of $3 \%$ on the hydroxylation of phenol. With the increase in catalyst consumption, the yield of dihydroxybenzene first increased and then decreased, but the yield decreased at the mass ratio of catalyst to phenol above 0.08 . This was because an excess of catalyst accelerated the decomposition of $\mathrm{H}_{2} \mathrm{O}_{2}$ and reduced the utilization rate of $\mathrm{H}_{2} \mathrm{O}_{2}$. The catalyst-to-phenol mass ratio of 0.053 was optimal.

3.3. Catalyst Stability. We did a blank experiment that only added catalyst, water, and hydrogen peroxide to test the stability of catalyst under reaction conditions. The reaction was as follows: $1.0 \mathrm{~g}$ of $\mathrm{Fe}(\mathrm{II}) / \mathrm{MOF}-5\left(3 \% \mathrm{Fe}^{2+}\right)$ was placed in $160 \mathrm{~mL}$ of hydrogen peroxide $(30 \%)$ and $300 \mathrm{~mL}$ of deionized water at $80^{\circ} \mathrm{C}$ with stirred for $1 \mathrm{~h}, 1.5 \mathrm{~h}$, and $2 \mathrm{~h}$, respectively. After filtered, they were vacuum dried at $80^{\circ} \mathrm{C}$ for $2 \mathrm{~h}$. The $\mathrm{XRD}$ of the samples is, respectively, shown in Figure 11.

Compared with the $\mathrm{Fe}(\mathrm{II}) / \mathrm{MOF}-5$ without the stability test, the feature peaks of the stability test $\mathrm{Fe}(\mathrm{II}) / \mathrm{MOF}-5$ 
TABLE 3: Effect of reaction temperature on phenol hydroxylation.

\begin{tabular}{lcccc}
\hline Temperature $\left({ }^{\circ} \mathrm{C}\right)$ & CAT (mass \%) & HQ yield (mass \%) & Dihydroxybenzene yield (mass \%) & CAT selectivity (mass \%) \\
\hline 50 & 0 & 0 & 0 & 0 \\
60 & 0 & 0 & 0 & 0 \\
70 & 42 & 6.4 & 48.4 & 85.4 \\
80 & 53.2 & 0 & 53.2 & 98.6 \\
\hline
\end{tabular}

TABLE 4: Effect of reaction time on the phenol hydroxylation.

\begin{tabular}{lcccc}
\hline Reaction time $(\mathrm{h})$ & $\begin{array}{c}\text { Catechol yield } \\
\text { (mass \%) }\end{array}$ & $\begin{array}{c}\text { Hydroquinone yield } \\
\text { (mass \%) }\end{array}$ & $\begin{array}{c}\text { Dihydroxybenzene yield } \\
\text { (mass \%) }\end{array}$ & $\begin{array}{c}\text { Catechol selectivity } \\
\text { (mass \%) }\end{array}$ \\
\hline 0.5 & 0 & 0 & 0 & 0 \\
1 & 36 & 0 & 36 & 100 \\
2 & 53.2 & 0 & 53.2 & 98.6 \\
3 & 48.7 & 0 & 48.7 & 95 \\
\hline
\end{tabular}

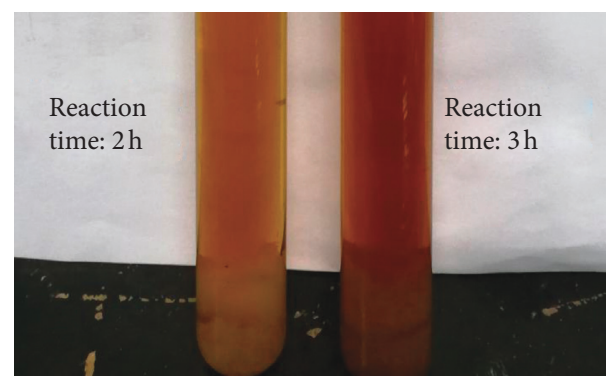

Figure 10: Color contrast diagram of reaction solution with different reaction times.

TABLE 5: Effect of catalyst dosage on the phenol hydroxylation.

\begin{tabular}{lcccc}
\hline $\begin{array}{l}\text { Ratio of catalyst to } \\
\text { phenol (mass \%) }\end{array}$ & $\begin{array}{c}\text { Catechol yield } \\
\text { (mass \%) }\end{array}$ & $\begin{array}{c}\text { Hydroquinone } \\
\text { yield (mass \%) }\end{array}$ & $\begin{array}{c}\text { Dihydroxybenzene } \\
\text { yield (mass \%) }\end{array}$ & Catechol selectivity (mass \%) \\
\hline 0.027 & 41.4 & 6.2 & 47.6 & 84.7 \\
0.053 & 53.2 & 0 & 53.2 & 98.6 \\
0.08 & 45 & 0 & 45 & 97.3 \\
0.107 & 26.2 & 0 & 26.2 & 97.4 \\
\hline
\end{tabular}

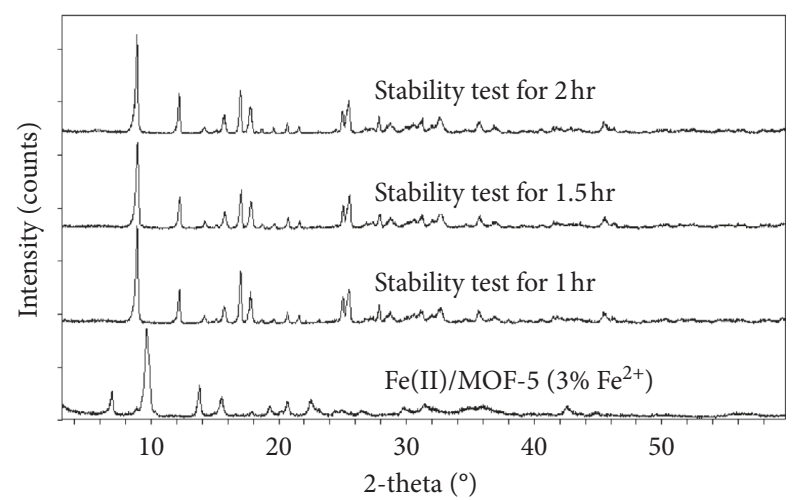

Figure 11: XRD contrast chart of Fe(II)/MOF-5 $\left(3 \% \mathrm{Fe}^{2+}\right)$ before and after the stability test.

around $7^{\circ}$ disappeared and the characteristic peak around $10^{\circ}$ slightly moved to left, but the feature peaks of $13^{\circ}$ and $14^{\circ}$ still keep. This may be because MOF-5 interacts with water molecules causing partial phase transitions. However, we found that the XRD peak shape of the catalysts did not change during different test periods $(1 \mathrm{~h}, 1.5 \mathrm{~h}$, and $2 \mathrm{~h})$ after the initial partial phase transitions. This indicates that the catalyst structure will remain stable in the reaction after the initial change.

Iron leaching is a serious problem for many iron-containing mesoporous and microporous materials. In order to check the leaching of the catalysts, after the reaction, a small amount of reaction liquid was taken out for filtration, and then the concentration of iron ions was measured by atomic absorption spectroscope. The leached iron ions ratio is calculated according to its concentration in reaction liquid. We found that the leached iron ions rates of are $18 \%$ after reaction. In addition to the natural leaching of iron ions, the reason for the high iron ion leaching is the structural change of MOF-5.

3.4. Hot Filtration Test. We also did the hot filtration test of the reaction. After reaction for one hour, the reaction liquid 
is removed and filtered out of the catalyst; then, the filtrate is continued to react under the same conditions for one hour. Content of products before and after filtration was analyzed by GC. It was found that the catechol yield after filtration was almost the same as that before filtration. This indicates that although a small amount of iron ions was leached in the reaction process, there was no catalytic activity after filtration.

\section{Conclusion}

$\mathrm{Fe}(\mathrm{II}) / \mathrm{MOF}-5$ catalysts were prepared by equivalent loading at low temperature. XRD analysis showed that the addition of Fe ions had little effect on the crystal structure of MOF-5. The results of test by EDS (energy dispersive spectrometry) showed that Fe was indeed loaded to the samples. The characterization by TEM and BET showed that Fe(II)/MOF5 had a very regular pore structure like MOF-5 and the pore size was about $1.2 \mathrm{~nm}$. It was found from phenol hydroxylation catalyzed by $\mathrm{Fe}(\mathrm{II}) / \mathrm{MOF}-5$ that $\mathrm{Fe}^{2+}$-supported MOF-5 could provide high catalytic activity and catechol selectivity for phenol hydroxylation. The yield of dihydroxybenzene was $53.2 \%$, and the selectivity of catechol was $98.6 \%$ at the $\mathrm{Fe}^{2+}$ content of $3 \mathrm{wt} . \%$, reaction temperature of $80^{\circ} \mathrm{C}$, reaction time of $2 \mathrm{~h}$, and catalyst-to-phenol mass ratio of 0.053 .

\section{Data Availability}

No data were used to support this study.

\section{Conflicts of Interest}

The authors declare that there are no conflicts of interest regarding the publication of this article.

\section{Acknowledgments}

This study was supported by the Key R\&D Projects of Hunan science and Technology (2017GK2020), the Key Laboratory of Green Catalysis and Reaction Engineering in Hunan High Universities, the Hunan 2011 Collaborative Innovation Center of Chemical Engineering Technology with Environmental Benignity and Effective Resource Utilization, the Hunan Key Laboratory of Chemical Process Integration and Optimization, the National \& Local United Engineering Research Centre for Chemical Process Integration, the Construct Program of the Key Discipline in Huaihua University, and the Huaihua University Science Research Project (HHUY2019-17). Also, the authors thank the Hunan Engineering Laboratory for Preparation Technology of Polyvinyl Alcohol (PVA) Fiber Material.

\section{References}

[1] H. Zhang, C. Tang, Y. Lv et al., "Synthesis, characterization, and catalytic performance of copper-containing SBA-15 in the phenol hydroxylation," Journal of Colloid and Interface Science, vol. 380, no. 1, pp. 16-24, 2012.
[2] X. Gao and X. Lu, "Research progress on catalysts for hydroxylation of phenol to dihydroxybenzen," Chemical Reagents, vol. 31, no. 7, pp. 519-530, 2009.

[3] H. Shao, X. Chen, B. Wang, J. Zhong, and C. Yang, "Synthesis and catalytic properties of MeAPO-11 molecular sieves for phenol hydroxylation," Acta Petrolei Sinica, vol. 28, no. 6, pp. 933-939, 2012.

[4] Y. Zhao, G. He, W. Dai, and H. Chen, "High catalytic activity in the phenol hydroxylation of magnetically separable $\mathrm{CuFe}_{2} \mathrm{O}_{4}$-reduced graphene oxide," Industrial \& Engineering Chemistry Research, vol. 53, no. 32, pp. 12566-12574, 2014.

[5] S. Shu and S. Zhang, "Development of catalysts for hydroxylation of phenol to dihydroxybenzene by hydrogen peroxide," Chemistry Bulletin, vol. 78, no. 8, pp. 702-709, 2015.

[6] H. Belarbi, Z. Lounis, A. Bengueddach, and P. Trens, "Influence of the particle size of Cu-ZSM-5 for the heterogeneous oxidation of bulky hydrocarbons," The European Physical Journal Special Topics, vol. 224, no. 9, pp. 1963-1976, 2015.

[7] I. Fatimah, "Preparation of $\mathrm{ZrO}_{2} / \mathrm{Al}_{2} \mathrm{O}_{3}$-montmorillonite composite as catalyst for phenol hydroxylation," Journal of Advanced Research, vol. 5, no. 6, pp. 663-670, 2014.

[8] B. P. Nethravathi, K. Ramakrishna Reddy, and K. N. Mahendra, "Catalytic activity of supported solid catalysts for phenol hydroxylation," Journal of Porous Materials, vol. 21, no. 3, pp. 285-291, 2014.

[9] H. Li, M. Eddaoudi, M. O'Keeffe, and O. M. Yaghi, "Design and synthesis of an exceptionally stable and highly porous metal-organic framework," Nature, vol. 402, no. 6759, pp. 276-279, 1999.

[10] Y. Zhao, "Preparation and catalytic performance for phenol hydroxylation of Fe-SBA-16 mesoporous molecular sieves," Chemical Industry and Engineering Progress, vol. 35, no. 2, pp. 187-191, 2016.

[11] T. Yu, S. Q. Zhang, C. M. Ding, and Z. B. Zhao, "Study on highly selective hydroxylation of phenol in the aqueous phase," Chemistry Bulletin, vol. 78, no. 4, p. 364, 2015.

[12] W. Zhang, Y. Wang, Y. Shen, M. Xie, and X. Guo, "Mesoporous zinc aluminate $\left(\mathrm{ZnAl}_{2} \mathrm{O}_{4}\right)$ nanocrystal: synthesis, structural characterization and catalytic performance towards phenol hydroxylation," Microporous and Mesoporous Materials, vol. 226, pp. 278-283, 2016.

[13] F. Adam, J.-T. Wong, and E.-P. Ng, "Fast catalytic oxidation of phenol over iron modified zeolite L nanocrystals," Chemical Engineering Journal, vol. 214, no. 1, pp. 63-67, 2013.

[14] Y. Q. Zheng, W. B. Tao, and K. H. Ding, "Synthesis and catalytic properties of catalyst Cd-MOF-cat for selective oxidation of phenol to hydroquinone," Industrial Catalysis, vol. 22, no. 4, p. 287, 2014.

[15] Y. C. Hu, "Synthesis of hydroquinone by phenol hydroxylation over as-Mo-V heleropoly salt catalyst," Journal of Petrochemical Universities, vol. 18, no. 1, pp. 11-13, 2005.

[16] Y. Zhan, L. Shen, C. Xu, W. Zhao, Y. Cao, and L. Jiang, "MOFderived porous $\mathrm{Fe}_{2} \mathrm{O}_{3}$ with controllable shapes and improved catalytic activities in $\mathrm{H}_{2} \mathrm{~S}$ selective oxidation," CrystEngComm, vol. 20, no. 25, pp. 3449-3454, 2018.

[17] S. Bhattacharjee, Y.-R. Lee, P. Puthiaraj, S.-M. Cho, and W.-S. Ahn, "Metal-organic frameworks for catalysis," $\mathrm{Ca}$ talysis Surveys from Asia, vol. 19, no. 4, pp. 203-222, 2015.

[18] J. Kim, S.-H. Kim, S.-T. Yang, and W.-S. Ahn, "Bench-scale preparation of $\mathrm{Cu}_{3}(\mathrm{BTC})_{2}$ by ethanol reflux: synthesis optimization and adsorption/catalytic applications," Microporous and Mesoporous Materials, vol. 161, no. 5, pp. 48-55, 2012. 
[19] J. Kim, S. Bhattacharjee, K.-E. Jeong, S.-Y. Jeong, and W.-S. Ahn, "Selective oxidation of tetralin over a chromium terephthalate metal organic framework, MIL-101," Chemical Communications, vol. 26, no. 26, p. 3904, 2009.

[20] S. Bhattacharjee, J.-S. Choi, S.-T. Yang, S. B. Choi, J. Kim, and W.-S. Ahn, "Solvothermal synthesis of Fe-MOF-74 and its catalytic properties in phenol hydroxylation," Journal of Nanoscience and Nanotechnology, vol. 10, no. 1, pp. 135-141, 2010.

[21] S.-N. Kim, J. Kim, H.-Y. Kim, H.-Y. Cho, and W.-S. Ahn, "Adsorption/catalytic properties of MIL-125 and NH2-MIL125," Catalysis Today, vol. 204, no. 1, pp. 85-93, 2013.

[22] Y.-R. Lee, S.-M. Cho, W.-S. Ahn, C.-H. Lee, K.-H. Lee, and W.-S. Cho, "Facile synthesis of an IRMOF-3 membrane on porous $\mathrm{Al}_{2} \mathrm{O}_{3}$ substrate via a sonochemical route," Microporous and Mesoporous Materials, vol. 213, no. 1, pp. 161-168, 2015.

[23] M. Faustini, J. Kim, G.-Y. Jeong et al., "Microfluidic approach toward continuous and ultrafast synthesis of metal-organic framework crystals and hetero structures in confined microdroplets," Journal of the American Chemical Society, vol. 135, no. 39, pp. 14619-14626, 2013.

[24] N. R. Shiju, A. H. Alberts, S. Khalid, D. R. Brown, and G. Rothenberg, "Mesoporous silica with site-isolated amine and phosphotungstic acid groups: a solid catalyst with tunable antagonistic functions for one-pot tandem reactions," Angewandte Chemie, vol. 123, no. 41, pp. 9789-9793, 2011.

[25] Y.-M. Chung, H.-Y. Kim, and W.-S. Ahn, "Friedel-crafts acylation of p-xylene over sulfonated zirconium terephthalates," Catalysis Letters, vol. 144, no. 5, pp. 817-824, 2014.

[26] J. Kim, S.-N. Kim, H.-G. Jang, G. Seo, and W.-S. Ahn, " $\mathrm{CO}_{2}$ cycloaddition of styrene oxide over MOF catalysts," Applied Catalysis A: General, vol. 453, no. 6, pp. 175-180, 2013.

[27] S. Bhattacharjee and W.-S. Ahn, "Palladium nanoparticles supported on MIL-101 as a recyclable catalyst in water-mediated Heck reaction," Journal of Nanoscience and Nanotechnology, vol. 15, no. 9, pp. 6856-6859, 2015.

[28] S. Bhattacharjee, Y.-R. Lee, and W.-S. Ahn, "Post-synthesis functionalization of a zeolitic imidazolate structure ZIF-90: a study on removal of $\mathrm{Hg}$ (II) from water and epoxidation of alkenes," CrystEngComm, vol. 17, no. 12, pp. 2575-2582, 2015.

[29] X. Chen, Y. Hou, H. Wang, Y. Cao, and J. He, "Facile deposition of $\mathrm{Pd}$ nanoparticles on carbon nanotube microparticles and their catalytic activity for suzuki coupling reactions," The Journal of Physical Chemistry C, vol. 112, no. 22, pp. 8172-8176, 2008.

[30] S. S. Kaye, A. Dailly, O. M. Yaghi, and J. R. Long, "Impact of preparation and handling on the hydrogen storage properties of $\mathrm{Zn}_{4} \mathrm{O}$ (1,4-benzenedicarboxylate) ${ }_{3}$ (MOF-5)," Journal of the American Chemical Society, vol. 129, no. 46, pp. 14176-14177, 2007.

[31] E. V. Perez, K. J. Balkus, J. P. Ferraris, and I. H. Musselman, "Mixed-matrix membranes containing MOF-5 for gas separations," Journal of Membrane Science, vol. 328, no. 1-2, pp. 165-173, 2009.

[32] S. Horike, M. Dincă, K. Tamaki, and J. R. Long, "Size-selective lewis acid catalysis in a microporous metal-organic framework with exposed $\mathrm{Mn}^{2+}$ coordination sites," Journal of the American Chemical Society, vol. 130, no. 18, pp. 5854-5855, 2008.

[33] U. Ravon, M. E. Domine, C. Gaudillère, A. DesmartinChomel, and D. Farrusseng, "MOF-5 as acid catalyst with shape selectivity properties," in Proceedings of the 4th
International FEZA Conference, vol. 174, no. 8, pp. 467-470, Paris, France, September 2008.

[34] W. Zhang, G. Lu, C. Cui et al., "A family of metal-organic frameworks exhibiting size-selective catalysis with encapsulated noble-metal nanoparticles," Advanced Materials, vol. 26, no. 24, pp. 4056-4060, 2014.

[35] C.-H. Kuo, Y. Tang, L.-Y. Chou et al., "Yolk-shell nanocrystal@ZIF-8 nanostructures for gas-phase heterogeneous catalysis with selectivity control," Journal of the American Chemical Society, vol. 134, no. 35, pp. 14345-14348, 2012.

[36] M. Müller, S. Turner, O. I. Lebedev, Y. Wang, G. van Tendeloo, and R. A. Fischer, "Au@MOF-5 and Au/ MO $@$ MOF-5 $(\mathrm{M}=\mathrm{Zn}, \mathrm{Ti} ; x=1,2)$ : preparation and microstructural characterisation," European Journal of Inorganic Chemistry, vol. 2011, no. 12, pp. 1876-1887, 2011.

[37] L. Ning, S. Liao, H. Cui, L. Yu, and X. Tong, "Selective conversion of renewable furfural with ethanol to produce furan-2-acrolein mediated by Pt@MOF-5," ACS Sustainable Chemistry \& Engineering, vol. 6, no. 1, pp. 135-142, 2017.

[38] F. Xamena, A. Abad, A. Corma, and H. Garcia, "MOFs as catalysts: activity, reusability and shape-selectivity of a $\mathrm{Pd}$ containing MOF," Journal of Catalysis, vol. 250, no. 2, pp. 294-298, 2007.

[39] M. Zhang, F. X. Yin, X. B. He, and G. R. Li, "Preparation of NiCo-MOF-74 and its electrocatalytic oxygen precipitation performance," Journal of Beijing University of Chemical Technology (Natural Science), vol. 46, no. 4, pp. 38-45, 2019.

[40] L. Liu, X. Tai, M. Liu, Y. Li, Y. Feng, and X. Sun, "Supported Au/MOF-5: a highly active catalyst for three-component coupling reactions," CIESC Journal, vol. 66, no. 5, pp. 17381747, 2015.

[41] Restu, Kartiko, Widi et al., "Hydroxylation of phenol with hydrogen peroxide catalyzed by $\mathrm{Fe}$ - and AIFe-bentonite," Chemistry and Chemical Engineering: English Version, vol. 3, no. 4, pp. 48-52, 2009.

[42] M. E. L. Preethi, S. Revathi, T. Sivakumar et al., "Phenol hydroxylation using Fe/Al-MCM-41 catalysts," Catalysis Letters, vol. 120, no. 1-2, pp. 56-64, 2008.

[43] M. S. Hamdy, G. Mul, W. Wei et al., "Fe, Co and Cu-incorporated TUD-1: synthesis, characterization and catalytic performance in $\mathrm{N}_{2} \mathrm{O}$ decomposition and cyclohexane oxidation," Catalysis Today, vol. 110, no. 3-4, pp. 264-271, 2005.

[44] M. N. Cele, H. B. Friedrich, and M. D. Bala, "A study of Fe(III) TPPCl encapsulated in zeolite $\mathrm{NaY}$ and $\mathrm{Fe}(\mathrm{III}) \mathrm{NaY}$ in the oxidation of n-octane, cyclohexane, 1-octene and 4-octene," Reaction Kinetics, Mechanisms and Catalysis, vol. 111, no. 2, pp. 737-750, 2014.

[45] S. X. Gao, N. Zhao, M. H. Shu, and S. N. Che, "Palladium nanoparticles supported on MOF-5: a highly active catalyst for a ligand- and copper- free sonogashira coupling reaction," Applied Catalysis A: General, vol. 388, no. 1-2, pp. 196-201, 2010.

[46] N. Zhao, H. P. Deng, and M. H. Shu, "Preparation and catalytic performance of Pd catalyst supported on MOF-5," Chinese Journal of Inorganic Chemistry, vol. 26, no. 7, pp. 1213-1217, 2010.

[47] Z. Zhao, Z. Li, and Y. S. L. Jerry, "Secondary growth synthesis of MOF-5 membranes by dip-coating nano-sized MOF-5 seeds," CIESC Journal, vol. 62, no. 2, pp. 507-514, 2011.

[48] H. Shao, X. Chen, B. Wang, J. Zhong, and C. Yang, "Synthesis and catalytic properties of MeAPO-11 molecular sieves for phenol hydroxylation," Acta Petrolei Sinica (Petroleum Processing Section), vol. 28, no. 6, pp. 933-939, 2012. 
[49] G. Wang, X. Wang, Y. Zhang et al., "Effect of hydrogen bonds on the static effect of nanofiltration process," Journal of Materials Science \& Engineering, vol. 27, no. 4, pp. 610-612, 2009.

[50] X. Zhang, J. Zhang, G. Zhang et al., "Formation and inhibition of phenolic tars in process for preparation of diphenols by the hydroxylatuion of phenol," Journal of Chemical Engineering of Chinese Universities, vol. 21, no. 2, pp. 257-261, 2007.

[51] B.-L. Xiang, L. Fu, Y. Li, and Y. Liu, "A new Fe(III)/MOF-5 (Ni) catalyst for highly selective synthesis of catechol from phenol and hydrogen peroxide," ChemistrySelect, vol. 4, no. 4, pp. 1502-1509, 2019.

[52] S. Buttha, S. Youngme, J. Wittayakun, and S. Loiha, "Formation of iron active species on HZSM- 5 catalysts by varying iron precursors for phenol hydroxylation," Molecular Catalysis, vol. 461, no. 26, pp. 2468-8231, 2018. 

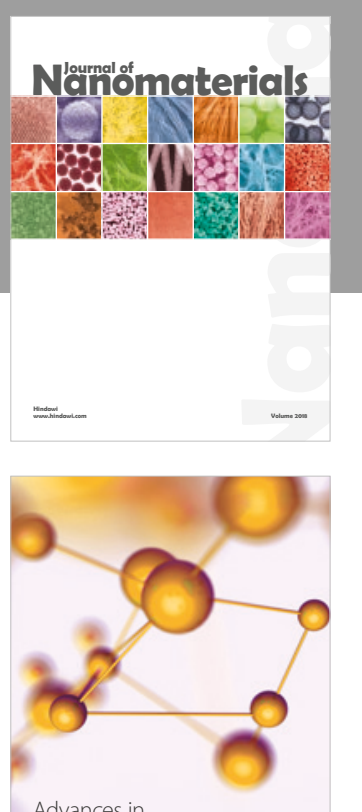

Physical Chemistry
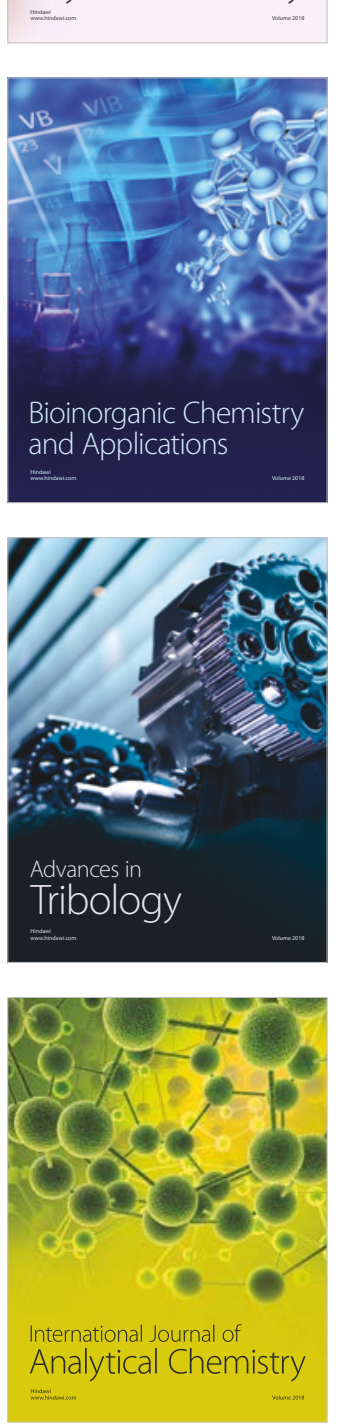

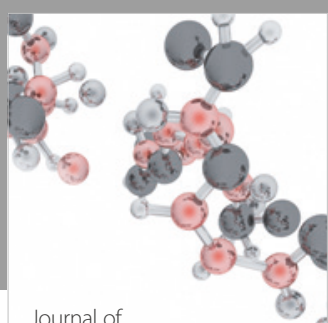

Analytical Methods

in Chemistry

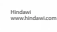

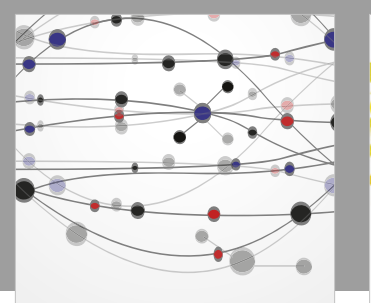

The Scientific World Journal

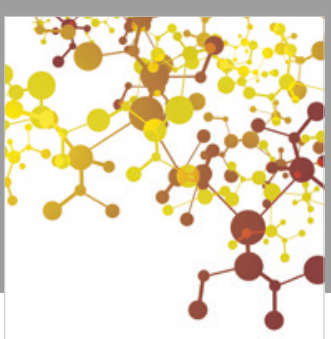

Journal of

Applied Chemistry
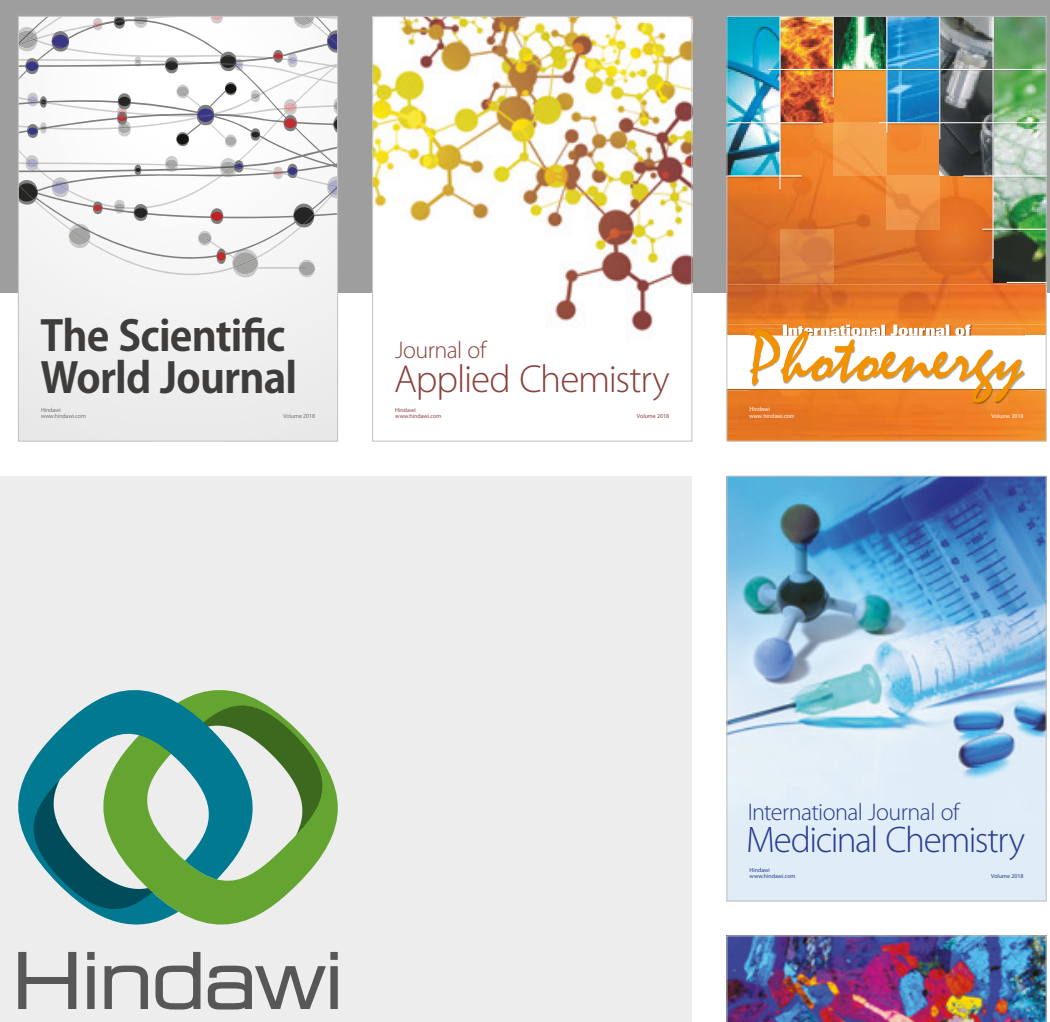

Submit your manuscripts at

www.hindawi.com
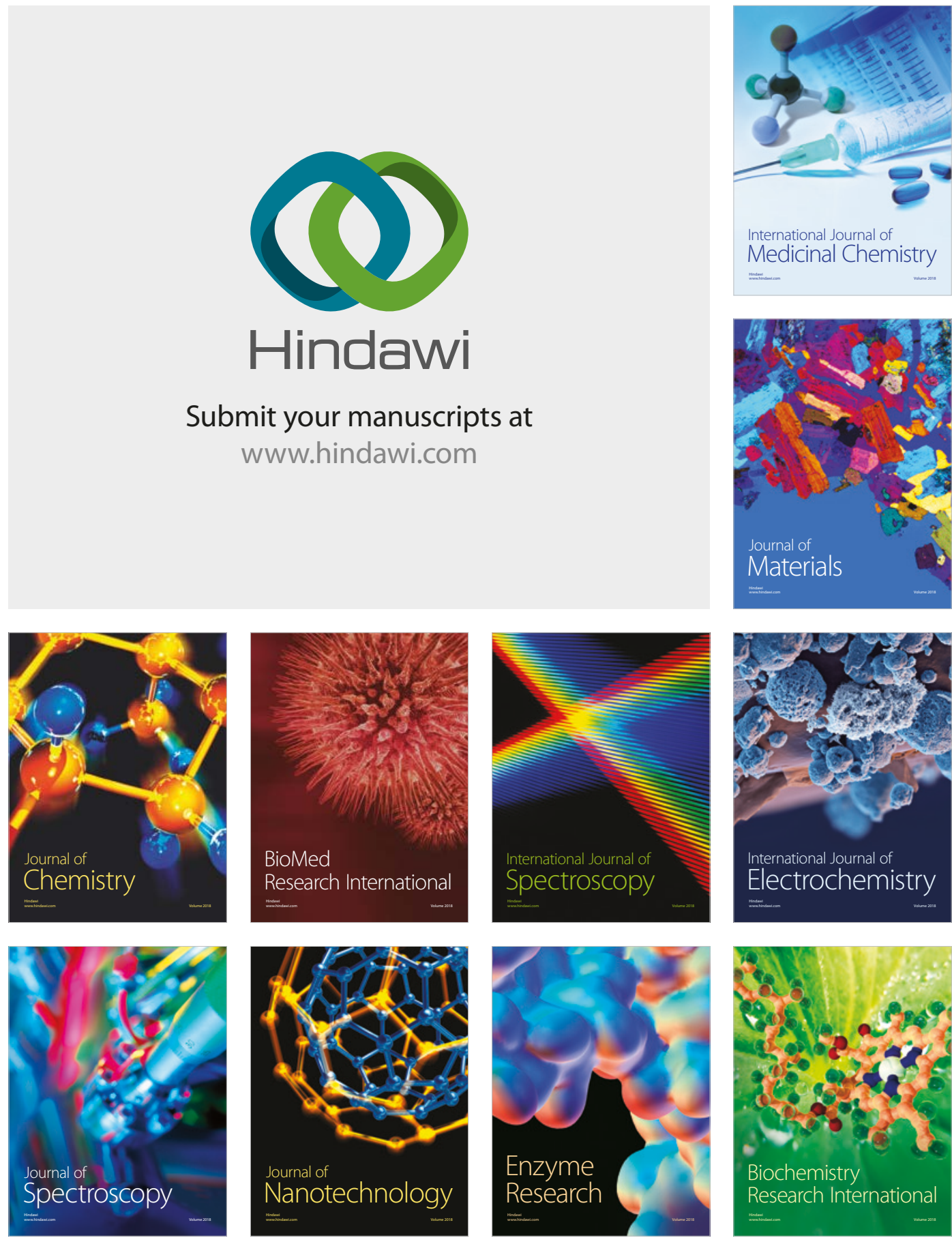
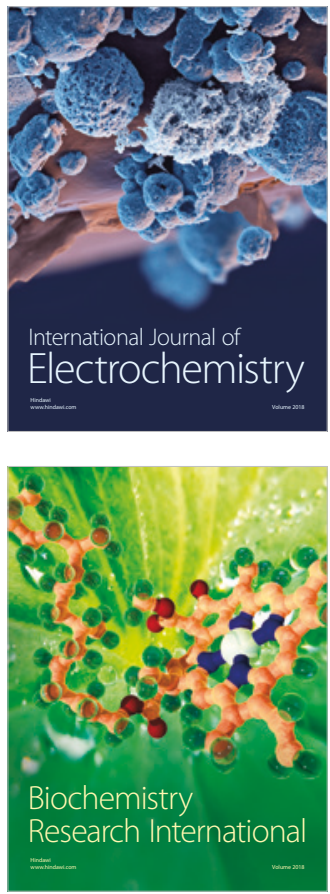